\title{
Assessment of chemical dissolution method for conservation of underwater archaeological ceramics
}

\author{
Nurul Hidayat Aprilita ${ }^{1, ~}$, Endang Tri Wahyuni ${ }^{1}$, Mahirta ${ }^{2}$, Farida Yulita Putri Yuani ${ }^{1}$, \\ Raisa Deborah $^{1}$ \\ ${ }^{1}$ Chemistry Department, Universitas Gadjah Mada, Sekip Utara Bulaksumur 21, Yogyakarta, 55281, Indonesia \\ ${ }^{2}$ Archaeology Department, Universitas Gadjah Mada, Nusantara Street 1, Bulaksumur, Yogyakarta, 55281, Indonesia
}

Email address:

nurul.hidayat@ugm.ac.id (N. H. Aprilita)

\section{To cite this article:}

Nurul Hidayat Aprilita, Endang Tri Wahyuni, Mahirta, Farida Yulita Putri Yuani, Raisa Deborah. Assessment of Chemical Dissolution Method for Conservation of Underwater Archaeological Ceramics. American Journal of Applied Chemistry. Vol. 2, No. 5, 2014, pp. 85-90.

doi: 10.11648/j.ajac.20140205.14

\begin{abstract}
The application of chemical dissolution for removal of sediment covering ceramics of underwater archaeology has been studied. The first step of this research was analysis and identification of the content of sediment covering ceramics of underwater archaeology using IR spectrophotometer, X-Ray Diffractometer, and Atomic absorption spectrophotometer. The second step was dissolution process of the sediment using water, $\mathrm{Na}_{2} \mathrm{EDTA}$, and $\mathrm{H}_{2} \mathrm{O}_{2}$ solution. In this step, the influences of dissolution time using water and various concentration of the $\mathrm{Na}_{2}$ EDTA and $\mathrm{H}_{2} \mathrm{O}_{2}$ solution have been evaluated. The result of this research showed that the sediment covering ceramics of underwater archaeology contains of organic compound, soluble salts of $\mathrm{Na}^{+}$and $\mathrm{K}^{+}$, and insoluble salts of $\mathrm{Ca}^{2+}, \mathrm{Mg}^{2+}$, and $\mathrm{Fe}^{3+}$. Increasing the dissolution time in water has considerably increased the dissolution of the $\mathrm{Na}^{+}$and $\mathrm{K}^{+}$salts from sediment. On the other hand, increasing of concentration $\mathrm{Na}_{2} \mathrm{EDTA}$ gives an increase in the $\mathrm{Ca}^{2+}, \mathrm{Mg}^{2+}$, and $\mathrm{Fe}^{3+}$ salts dissolution from the sediment. The optimum concentration of $\mathrm{H}_{2} \mathrm{O}_{2}$ solution for dissolving organic compound is $30 \%$.
\end{abstract}

Keywords: Chemical, Dissolution, Conservation, Archaeological, Ceramic

\section{Introduction}

The UNESCO has reported that the number of Underwater Cultural Heritage Site (UCHS) in the world is approximately 3 million. Among them, 3000 sites were found in Indonesian waters. In Indonesia, 463 sites have discovered and some have been lifted up from the sea. UCHS usually was made of wood, metal, glass, and ceramics. Ceramic types are most commonly found in Indonesia. UCHS was normally covered by marine sediments that have been buried in the ocean floor for a long time. UCHS have undergone physical and chemical reactions in the environment which is resulted from the formation of sediment that covers the surface of the ceramic. This reaction is able to degrade the quality and durability of the ceramics [1]. Sediments are created in aquatic system because there are organisms that have suitable habitat in wood, stone and ceramic-based archaeology sites [2]. The factors causing the deposition of sediments on the UCHS includes the activity of living organisms such as microorganisms and fungi, the pressure in the water, as well as the presence of salt [3].
Sediments can also containing lime and silica. Lime and silica in sediments are usually removed mechanically using a chisel, water pressure, and others [4]. This method has a risk of damaging the cultural heritage sites if this is not done carefully.

The first step that must be done after the lifting of UCHS object is cleaning the sediment. The ceramic surface covered by hard deposits cannot be simply released by spraying water. The sediment contains various organic and inorganic chemical compounds which have been formed for a long time and become very hard. In general, hard deposits on the ceramic surface can be organic, inorganic compounds or soluble and insoluble salts, as well as brick-red stains of iron oxide and turquoise of copper oxide [5]. Removal of solids in the form of organic compounds can be done with a solution of nitric acid, sulfuric acid and perchloric acid [6], which are a strong oxidizing agents and may damage or dissolve the ceramics. Instead of these strong acids, other strong oxidizing agent such as hydrogen peroxide $\left(\mathrm{H}_{2} \mathrm{O}_{2}\right)$ may also be used [7]. This agent is very strong oxidation substance which makes it a very 
effective way to be used in the cleaning of the crust.

Considering the high historical value, the cleanup of hard deposits should be done immediately to prevent the damage of UCHS. In addition, with the available of cleaned UCHS makes archaeological studies become faster and more accurate. Removal of hard deposits on the surface of the ceramic UCHS is a very important part in conservation. UCHS conservation steps generally include documentation, analysis, cleaning, desalination, consolidation, and unification of fragments [5]. On the basis of the fact that chemical cleaning stage using the basic concepts of chemistry and ceramics are the most widely found in UCHS, this research is focused on conservation of UCHS Ceramics.

The cleanup protocol of UCHS, which has been conducted by the Directorate for Cultural Heritage Preservation and Museum, Indonesia is by scrubbing (mechanical), immersion in water, and in acid. This process is less systematic, the cleaning result is not optimal and it may damage the ceramics.

Selection a suitable solvent to clean UCHS is based on the type and amount of chemicals that formed hard deposits. The good solvent can clean hard deposits effectively without causing damage to the ceramic itself. Kasnowiharjo [8] has cleaned UCHS using $\mathrm{HCl}$ and $\mathrm{H}_{2} \mathrm{SO}_{4}$ but the acids was reported to damage the surface of ceramics.

Based on the above facts, this research was conducted as part of the systematic conservation techniques. Systematic conservation consists of qualitative and quantitative analysis of chemical compound in hard deposits and clean-up procedure with the dissolution method/chemical leaching using a suitable solvent under optimal conditions. In this study, the organic compounds in sediments was cleaned with hydrogen peroxide, soluble salts using a slightly acidic water, insoluble salts and iron/copper oxide with oxalic acid and ethylene diamine tetra acetic acids (EDTA). Appropriate dissolution conditions systematically studied by the optimization of time, concentration and $\mathrm{pH}$ of the solvent. This research is relatively new to the field of conservation and the application of chemical concepts in UCHS. This research is expected to give benefit and may be developed as a standard method in conservation of UCHS ceramics.

\section{Experimental Details}

\subsection{Materials}

Materials used in this research are UCHS ceramics samples provided by the Directorate of Cultural Heritage and Museum Republic of Indonesia, oxalic acid $\left(\mathrm{H}_{2} \mathrm{C}_{2} \mathrm{O}_{4}\right)$, Na-EDTA salts, hydrochloric acid $(\mathrm{HCl})$, nitric acid $\left(\mathrm{HNO}_{3}\right)$, and the spectrosol standard solution of $\mathrm{KNO}_{3}, \mathrm{NaNO}_{3}, \mathrm{Ca}\left(\mathrm{NO}_{3}\right)_{2}$, $\mathrm{Mg}\left(\mathrm{NO}_{3}\right)_{2}, \mathrm{Fe}\left(\mathrm{NO}_{3}\right)_{3}$, and $\mathrm{Cu}\left(\mathrm{NO}_{3}\right)_{2}$ elements. The reagents are pro analysis (pa) grade.

\subsection{Instrumentation}

Infra-Red Spectrophotometer was used to identify functional groups in sediments. Type of minerals in sediments was identified by XRD and the metal contents were analyzed by AAS.

\subsection{Procedure}

\subsubsection{Identification and Analysis of Sediments in Ceramic}

Infra-Red Spectrophotometer was used to identify functional groups in sediments. Type of minerals in sediments was identified by XRD and the metal contents was analyzed by AAS.

\subsubsection{Dissolution Methods}

\subsubsection{Organic Substances}

UCHS ceramic plate covered by hard deposits was weighed accurately $\left(\mathrm{W}_{0}\right)$. The ceramic plate was than immersed in a solution of $10-25 \% \mathrm{H}_{2} \mathrm{O}_{2}$ for 24 hours. After cleaning process, the ceramics was dried warmly and weighed to a constant weight $\left(\mathrm{W}_{1}\right)$. Organic sediment weight lost was calculated by the formula:

$$
\frac{W_{o}-W_{1}}{W_{o}} \times 100
$$

\subsubsection{Soluble Salts}

UCHS ceramic plate covered by hard deposits was soaked in water and than nitric acid or hydrochloric acid was added slowly until $\mathrm{pH}$ of 5 . Every 2 hours, $\mathrm{Na}$ and $\mathrm{K}$ from soluble salts was analysed by AAS until there are no more soluble salts were observed

\subsubsection{Insoluble Salts Using Oxalic Acid}

UCHS ceramic plate covered by hard deposits was weighed accurately $\left(\mathrm{W}_{0}\right)$. And then, the ceramic plate was immersed in a solution of 1,5 and $10 \mathrm{M} \mathrm{H}_{2} \mathrm{C}_{2} \mathrm{O}_{4}$ for various times, e.g. 10, 24 and 48 hours. After the cleaning process, the ceramics was dried and weighed to a constant weight $\left(\mathrm{W}_{1}\right)$. Oxalic acid solution was analyzed that has been used for the dissolution by AAS to determine the amount of releasing $\mathrm{Ca}$ and $\mathrm{Mg}$ that release from sediment.

\subsubsection{Insoluble Salts Using EDTA Solution}

UCHS ceramic plate covered by hard deposits was weighed accurately $\left(\mathrm{W}_{0}\right)$. And then, the ceramic plate was immersed in a solution of 5, 10, and $15 \%$ EDTA for various times of 10, 24 and 48 hours. After the cleaning process, the ceramics was dried and weighed to a constant weight $\left(\mathrm{W}_{1}\right)$. The used EDTA solution was analyzed by AAS to determine the amount of $\mathrm{Ca}$ and $\mathrm{Mg}$ that release from sediment. The same procedure was also done for the cleaning of copper oxide dan iron oxide.

\section{Results and Discussion}

\subsection{Analysis and Identification and Analysis of Sediment in Ceramics}

Identification of the sediment in UCHS ceramic using infrared (IR) spectrophotometric method was conducted to determine the organic compounds contained in the sediments. IR spectrum is presented in Figure 1. 


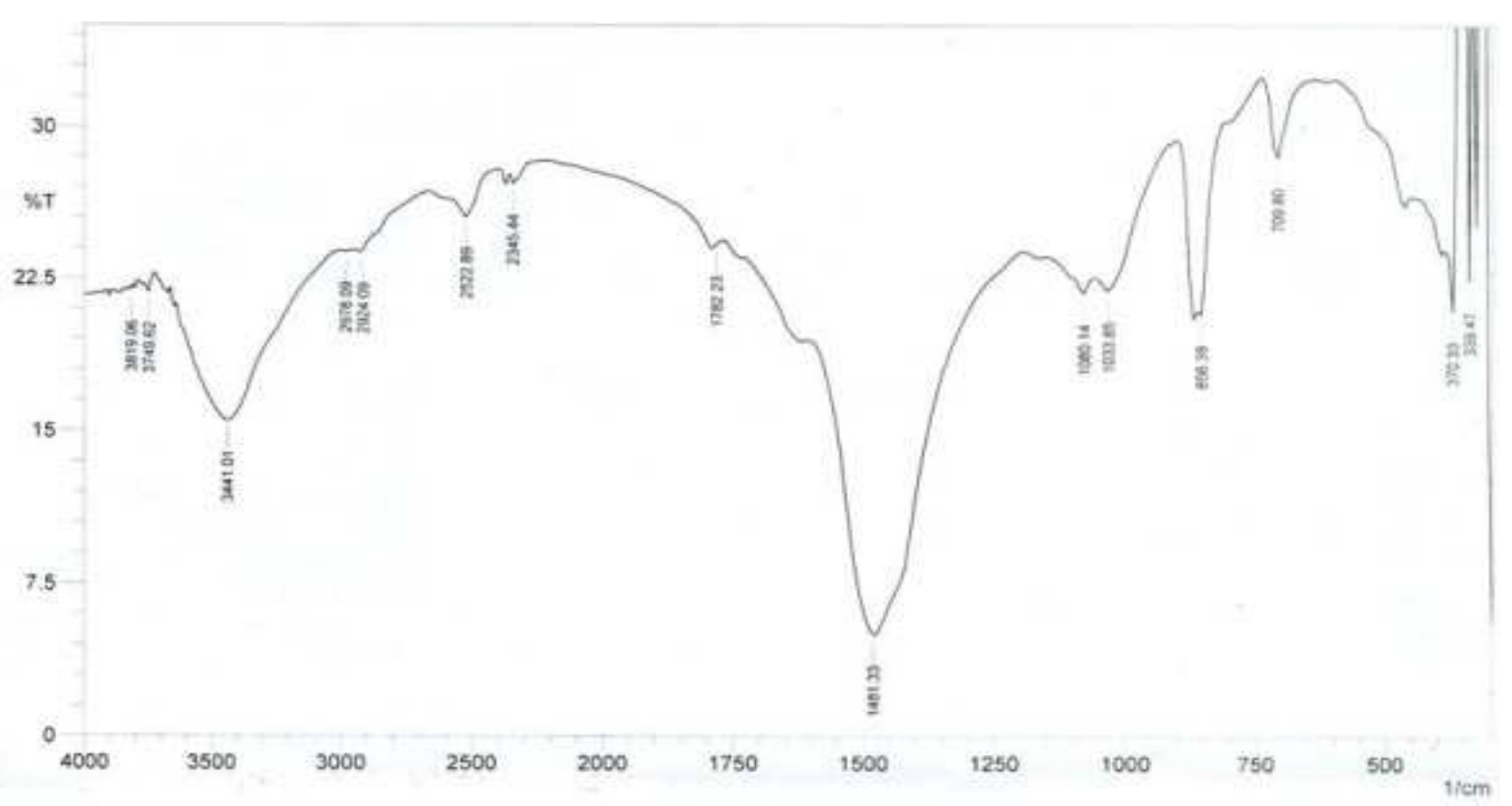

Fig 1. FTIR spectra of deposits in ceramics

Absorption bands at wave numbers of $3441 \mathrm{~cm}^{-1}$ shows stretching vibration of O-H group of the alcohol or amine $\mathrm{N}-\mathrm{H}$ group. Absorption at $2978 \mathrm{~cm}^{-1}$ shows the alkane $\mathrm{C}-\mathrm{H}$ stretching vibration. Absorption at 2522 and $1481 \mathrm{~cm}^{-1}$ shows the absorption of the carboxylic $\mathrm{O}-\mathrm{H}$ group and aromatic $\mathrm{C}-\mathrm{H}$. In addition, absorption at wavenumber of $856 \mathrm{~cm}^{-1}$ is observed due to bending vibration of the alkene and $=\mathrm{CH}$ stretching vibration of alcohol in the C-O group in $1080 \mathrm{~cm}^{-1}$.

Based on the identification of IR spectra, it can be interpreted that there are several functional groups present in ceramic sediments such as hydroxyl group of alcohol, -CO group, and $-\mathrm{CH}$ alkane indicating the presence of organic compounds in sediment. The presence of organic compounds in sediments is coming from biota and/or marine microorganisms. They lived in UCHS ceramic until the end of the life cycle of the biota or microorganisms for hundred years.

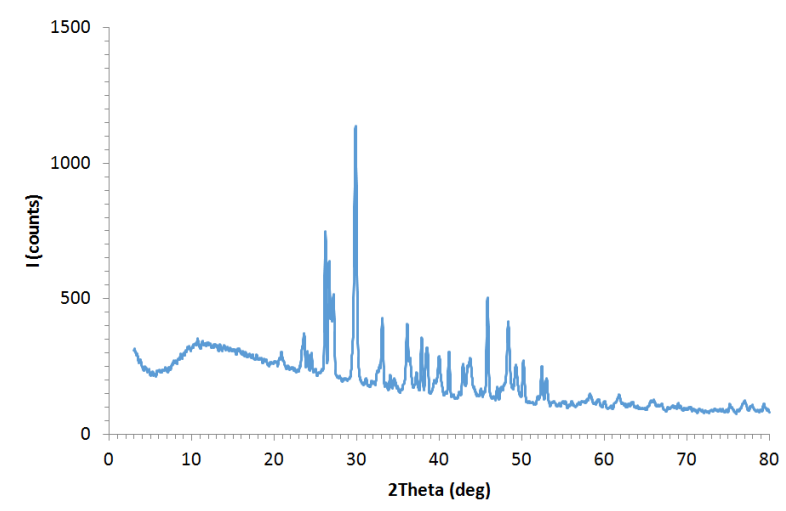

Fig 2. Diffractogram of sediment in UCHS sample

Identification of sediment deposits in UCHS ceramic also conducted by means of X-ray diffractometer with $\mathrm{Cu} \mathrm{K \alpha}$ radiation at an angle of $2 \theta=3-80^{\circ}$. X-ray diffractogram is presented in Figure 2.

Figure 2 shows 10 peaks of the sample with the highest intensity, which is then be compared with the standard XRD data from JCPDS minerals. Detailed comparison of sample peaks with those of mineral standards is presented in Table 1a and $1 b$.

From Table 1, it can be seen that the sediments samples analyzed by XRD were similar to $\mathrm{Ca}_{3}\left(\mathrm{PO}_{4}\right)_{2}, \mathrm{CaCl}_{2}, \mathrm{CaO}, \mathrm{Fe}_{2} \mathrm{O}_{3}$, $\mathrm{FeCl}_{3}, \mathrm{MgSO}_{4}, \mathrm{NaCl}$, dan $\mathrm{KCl}$. Thus, it can be concluded that the sediment deposits in a UCHS ceramics were $\mathrm{Na}, \mathrm{K}, \mathrm{Ca}, \mathrm{Mg}$, and $\mathrm{Fe}$ metals that came from salts such as $\mathrm{Ca}_{3}\left(\mathrm{PO}_{4}\right)_{2}, \mathrm{CaCl}_{2}$, $\mathrm{CaO}, \mathrm{Fe}_{2} \mathrm{O}_{3}, \mathrm{FeCl}_{3}, \mathrm{MgSO}_{4}, \mathrm{NaCl}$, dan $\mathrm{KCl}$. Determination of metal content in the sediment was also made using wet digestion with concentrated $\mathrm{HNO}_{3}$ and analyzed by AAS. The result of analysis is presented in Table 2.

Table 1a. Data of $d$-spacing from the 10 highest peaks in the sediment samples and mineral standards from JCPDS

\begin{tabular}{|c|c|c|c|c|c|c|c|}
\hline \multirow{2}{*}{ Peak } & \multirow{2}{*}{ d (§) sample } & \multicolumn{6}{|c|}{ Mineral Standards from JCPDS ( $(\AA)$} \\
\hline & & $\mathrm{NaCl}$ & KCl & $\mathrm{CaO}$ & MgO & $\mathrm{FeO}$ & $\mathrm{Fe}_{2} \mathrm{O}_{3}$ \\
\hline 1 & 2.995 & & & & & & 2.967 \\
\hline 2 & 3.401 & & & & & & \\
\hline 3 & 1.979 & & & & & & \\
\hline 4 & 3.278 & 3.258 & & & & & \\
\hline 5 & 1.882 & & & & & & \\
\hline 6 & 2.706 & & & 2.778 & & & \\
\hline 7 & 2.487 & & & & & 2.49 & \\
\hline 8 & 3.312 & & & & & & \\
\hline 9 & 2.376 & & & & & & \\
\hline 10 & 2.191 & & 2.186 & & & 2.153 & \\
\hline
\end{tabular}


Tabel 1b. Data of d-spacing from the 10 highest peaks in the sediments samples and mineral standards from JCPDS

\begin{tabular}{|c|c|c|c|c|c|c|c|c|c|}
\hline \multirow{2}{*}{ Peak } & \multirow{2}{*}{ d (§) Sample } & \multicolumn{8}{|c|}{ Mineral Standards from JCPDS $(\AA)$} \\
\hline & & $\mathrm{MgCO}_{3}$ & $\mathrm{FeCO}_{3}$ & $\mathrm{MgSO}_{4}$ & $\mathrm{Na}_{2} \mathrm{SO}_{4}$ & $\mathrm{CaSO}_{4}$ & $\mathrm{Na}_{2} \mathrm{CO}_{3}$ & $\mathrm{CaCl}_{2}$ & $\mathrm{CaCO}_{3}$ \\
\hline 1 & 2.992 & 2.984 & & & & & & & 2.917 \\
\hline 2 & 3.401 & & & 3.398 & & & & 3.420 & \\
\hline 3 & 1.979 & & 1.965 & & & & & & \\
\hline 4 & 3.278 & & & & & & & & \\
\hline 5 & 1.882 & & & 1.877 & 1.891 & & & & \\
\hline 6 & 2.706 & & & & & & & & \\
\hline 7 & 2.487 & & & & 2.475 & & & & \\
\hline 8 & 3.312 & & & 3.304 & & & & & \\
\hline 9 & 2.376 & & & & & & & & 2.375 \\
\hline 10 & 2.191 & & & & & 2.183 & 2.181 & & \\
\hline
\end{tabular}

Table 2. Metal composition of sediments in UCHS ceramics

\begin{tabular}{lll}
\hline Metal & Concentration $(\mathbf{m g} / \mathbf{g})$ & Concentration $\% \mathbf{b} / \mathbf{b}$ \\
\hline $\mathrm{Ca}$ & 386.457 & 38.646 \\
$\mathrm{Mg}$ & 0.339 & 0.034 \\
$\mathrm{Fe}$ & 1.852 & 0.185 \\
$\mathrm{Na}$ & 0.363 & 0.036 \\
$\mathrm{~K}$ & 0.178 & 0.018 \\
\hline
\end{tabular}

Calcium is the most abundant metal in sediment of UCHS ceramics followed by Fe. This is consistent with the XRD analysis data which show that $\mathrm{Ca}$ is in the form of $\mathrm{Ca}_{3}\left(\mathrm{PO}_{4}\right)_{2}$, $\mathrm{CaCl}_{2}, \mathrm{CaO}$, and $\mathrm{Fe}$ in the form of $\mathrm{Fe}_{2} \mathrm{O}_{3}$ dan $\mathrm{FeCl}_{3}$.

\subsection{Dissolution Method of Sediment Deposits for Cleaning UCHS Ceramics}

Sediment cleanup process on UCHS ceramic was carried out in several stages, which is begun by dissolving soluble salt compounds using water solvent, followed by dissolution of insoluble salt using EDTA. Furthermore, organic compounds were dissolved with $\mathrm{H}_{2} \mathrm{O}_{2}$ solvent. This is done because the ultimate goal of this research is to clean the sediments, so the method should be done gradually to make maximally cleaning process.

\subsubsection{Dissolution Soluble-Salt Compounds in Sediment Deposits using Water Solvent}

Cleaning process of soluble salt in sediments deposit from UCHS ceramics such as $\mathrm{NaCl}$ and $\mathrm{KCl}$ can be done by dissolving the salts in water. This process is affected by dissolution time. Therefore in this research, the dissolution time was varied. Dissolution of soluble-salt compound of ceramic sediments was indicated by the reduced weight of the ceramic as the function of dissolution time. The results are shown in Table 3.

Table 3. Weight loss of UCHS ceramic sediments as the function of dissolution time

\begin{tabular}{lll}
\hline T (hour) & W $_{\mathbf{0}}$ (gram) & $\mathbf{W}_{\mathbf{t}}$ (gram) \\
\hline 2 & 56.15 & 56.08 \\
5 & 56.08 & 56.07 \\
7 & 56.07 & 56.03 \\
24 & 56.03 & 56.02 \\
\hline
\end{tabular}

$\mathrm{W}_{\mathrm{o}}=$ initial weight, $\mathrm{W}_{\mathrm{t}}=$ final weight
Dissolved $\mathrm{Na}$ and $\mathrm{K}$ were analyzed by atomic absorption spectroscopy and the results are presented in figure 3 . Generally, the longer the contact time, the greater the solubility of $\mathrm{Na}$ and $\mathrm{K}$. Longer reaction time increase the number of active species and $\mathrm{Na}$ and $\mathrm{K}$ metal dissolution in the sediments becoming more effective. $\mathrm{Na}$ and $\mathrm{K}$ leaching process on ceramic sediments by water can take place through the mechanism of protonation, where the dissolution process begins with the absorption of $\mathrm{H}^{+}$or $\mathrm{OH}^{-}$ions on the surface of sediments forming the active species [9]. Formation of active species can polarize and weaken the bonding of $\mathrm{Na}$ and $\mathrm{K}$ from their compounds that may eventually leads to the dissolution of $\mathrm{Na}$ and $\mathrm{K}$.

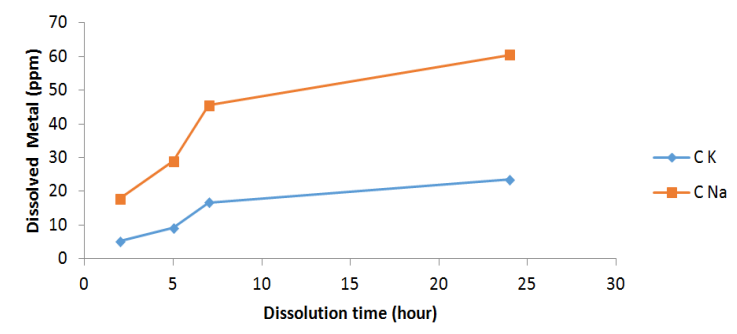

Fig 3. Effect of time on Na and $\mathrm{K}$ dissolution in water solvent.

\subsubsection{Dissolution of Insoluble Salt in Ceramic Sediment Using $\mathrm{Na}_{2} \mathrm{EDTA}$}

Cleaning ceramic sediments from insoluble salts, such as $\mathrm{Ca}, \mathrm{Mg}$, and Fe salts can be done by dissolving it in $\mathrm{Na}_{2}$ EDTA. Dissolution of insoluble salt was indicated by the reduced weight of the ceramics at variation of $\mathrm{Na}_{2}$ EDTA concentration. The results are shown in Table 4. Effectiveness of dissolution methods was indicated by the amount of dissolved metals in the EDTA. The result is presented in Figure 4. The higher concentration of EDTA increases significantly the number of metal dissolution as shown in Figure 4.

Table 4. Weight loss of ceramic sediments with variation of $\mathrm{Na}_{2}$ EDTA concentration

\begin{tabular}{llll}
\hline Concetration (M) & Wo (gram) & Wt (gram) & Wo-Wt (gram) \\
\hline 0.01 & 56.01 & 55.86 & 0.15 \\
0.03 & 55.86 & 55.49 & 0.37 \\
0.05 & 55.49 & 54.73 & 0.76 \\
0.1 & 52.38 & 51.12 & 1.26 \\
\hline
\end{tabular}

$\mathrm{W}_{\mathrm{o}}=$ initial weight, $\mathrm{W}_{\mathrm{t}}=$ final weight 
The dissolution process of $\mathrm{Ca}, \mathrm{Mg}$, and Fe metals with EDTA solution involves the formation of a complex in the solvent medium containing ligands. Reaction through complex formation between the metal and the ligand induces dissolution. The ligands form chelate rings with the metal oxide that increases the solubility of metals in solution (Stumm and Morgan, 1981).

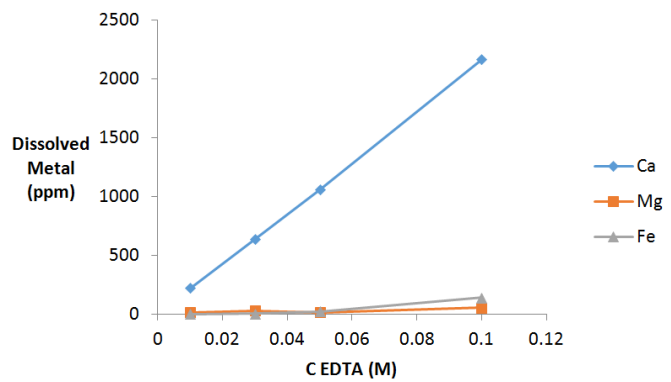

Fig 4. The relationship between concentrations of EDTA and the dissolution amount of $\mathrm{Ca}, \mathrm{Mg}$, and $\mathrm{Fe}$

\subsubsection{Dissolution of Organic Compounds in Ceramic Sediment by $\mathrm{H}_{2} \mathrm{O}_{2}$}

Cleaning organic compounds in ceramic sediments can be carried out by dissolving it in a $\mathrm{H}_{2} \mathrm{O}_{2}$ solvent. Leaching of organic compounds from sediments was indicated by weight loss as $\mathrm{H}_{2} \mathrm{O}_{2}$ concentration was varied. The results are of experiment shown in Table 5.

Table 5. Weight loss of ceramic sediments dissolved in variation of $\mathrm{H}_{2} \mathrm{O}_{2}$ concentration

\begin{tabular}{lll}
\hline Concentration (\%) & Wo (gram) & Wt (gram) \\
\hline 5 & 53.24 & 53.15 \\
10 & 53.15 & 53.04 \\
15 & 53.04 & 52.97 \\
20 & 52.97 & 52.92 \\
30 & 49.96 & 49.88 \\
\hline
\end{tabular}

$\mathrm{W}_{\mathrm{o}}=$ initial weight, $\mathrm{W}_{\mathrm{t}}=$ final weight

The weight of ceramic decreased after the immersion of it in $\mathrm{H}_{2} \mathrm{O}_{2}$. Organic compounds in ceramic sediment were oxidized by $\mathrm{H}_{2} \mathrm{O}_{2}$ and break down into smaller molecule and separated from ceramics. The relationship between the concentration of $\mathrm{H}_{2} \mathrm{O}_{2}$ and weight of dissolved organic compounds is shown in Figure 5.

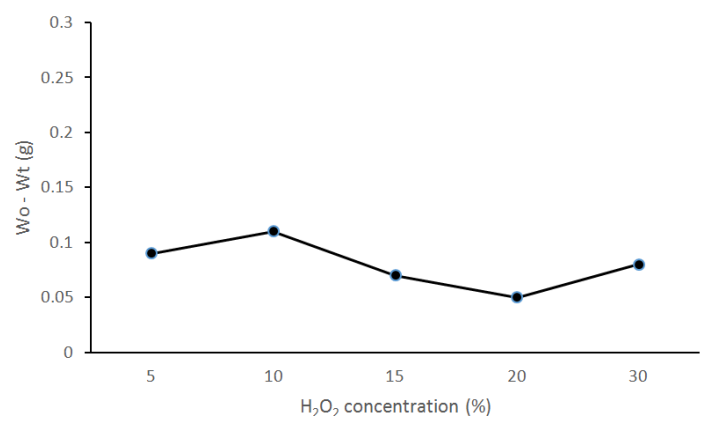

Fig 5. The relationship between the concentration of $\mathrm{H}_{2} \mathrm{O}_{2}$ and weight of dissolved organic compounds (Wo-Wt)
Dissolution of ceramics in $\mathrm{H}_{2} \mathrm{O}_{2}$ were performed in acidic solution. In this dissolution, $\mathrm{H}_{2} \mathrm{O}_{2}$ acts as an oxidizing agent of organic compounds. Reaction of $\mathrm{H}_{2} \mathrm{O}_{2}$ in solution can be written as follows:

$$
\mathrm{H}_{2} \mathrm{O}_{2}+2 \mathrm{H}^{+}+2 \mathrm{e} \rightleftharpoons 2 \mathrm{H}_{2} \mathrm{O} \quad \mathrm{E}_{h}^{\circ}=+1.77 \mathrm{~V}
$$

The physical appearance of the UCHS ceramics prior to cleaning with chemical solvent method is shown in Figure 6 and those of cleaning results of the UCHS is shown in Figure 6 and 7.

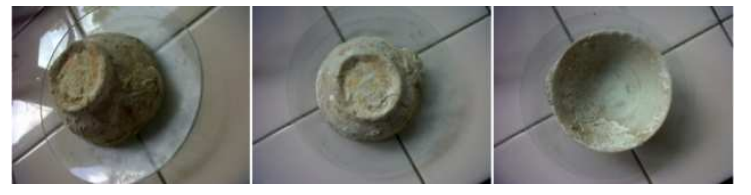

Fig 6. Ceramics before cleaning with chemical dissolution method

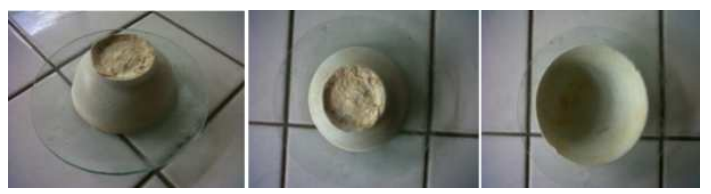

Fig 7. Ceramics after cleaning with chemical dissolution method

From Fig 6 and 7, it is shown that the ceramics after cleaning with chemical solvent method using water, EDTA, and $\mathrm{H}_{2} \mathrm{O}_{2}$ subsequently is cleaner than before. The ceramic remains in good condition and not damage after cleaning with solvent method using water, EDTA, and $\mathrm{H}_{2} \mathrm{O}_{2}$. The chemical dissolution methods can be used as an effective cleaning method for conservation efforts.

\section{Conclusion}

The result of this research showed that the sediment covering ceramic of underwater archaeology contains of organic compound, soluble salt of $\mathrm{Na}$ and $\mathrm{K}$, and insoluble salt of $\mathrm{Ca}, \mathrm{Mg}$, and $\mathrm{Fe}$. Increasing the dissolution time in water or aqueous solution has considerably increased the dissolution of the $\mathrm{Na}$ and $\mathrm{K}$ from sediment. Increasing of concentration $\mathrm{Na}_{2}$ EDTA gives an increase in the $\mathrm{Ca}, \mathrm{Mg}$, and $\mathrm{Fe}$ dissolution from the sediment. The optimum concentration of $\mathrm{H}_{2} \mathrm{O}_{2}$ solution for dissolving organic compound has been found to be $30 \%$. Chemical dissolution method of sediments covering ceramic UCHS using water, EDTA, and $\mathrm{H}_{2} \mathrm{O}_{2}$ can be used as an effective cleaning method for ceramic conservation efforts.

\section{Acknowledgements}

Supporting grant from LPPM Universitas Gadjah Mada through Penelitian Unggulan Perguruan Tinggi (PUPT UGM) is gratefully acknowledged

\section{References}

[1] Smith, H.D. and Couper, A.D., The management of Underwater Cultural Heritage”, J. Archaeolog. Sci, 2003, 4, 25-33. 
[2] Hall, K., Conservation of Marine Finds. Practical Guides for Archaeological Conservation and Site Preservation nb. 20, Japanese Institute of Anatolian Archaeology, 2002

[3] Mustaćek, M, Causes of the Decay of Archaeological Material, International Centre for Underwather Archaeology in Zadar, Zadar, 2011.

[4] Ćurković, M., Ceramic, Stone and Glass Archaeological Material, International Centre for Underwather Archaeology in Zadar, Zadar, 2011

[5] Luka, B., Ćurković, M., Jelić A., Jozić A., Mustaček M., Perin T., and Pešić M., Conservation of Underwater Archeological Finds Manual, International Centre for Underwater Archaeology in Zadar, Zadar, 2011.
[6] Skoog,D.A., West, D.M., and Holler, F.J., Analytical Chemistry : An Introduction, $6^{\text {th }}$ ed., Saunders College Publlishing, Tokyo, 1986.

[7] Cotton, F.E., Wilkinson, G., and Gaus, P.L., Basic Inorganic Chemistry, $2^{\text {nd }}$ ed, John Wiley and Sons, New York, 1986.

[8] Kasnowiharjo, G., Experimental Cleaning on Ceramics Results of Underwater Archaeological Excavation, Majalah Arkeologi Indonesia, 2011.

[9] Stumm, W., and Morgan, J.J., Aquatic Chemistry: An Introduction Emphasizing Chemical Equilibria in Natural Waters, John Wiley and Sonc Inc., New York, 1981. 